УдК 621.315:621.039.58

\author{
Е. А. Иокст, В. А. Иокст, Л. С. Ивашова, \\ К. М. Ефимова, В. В. Левакин
}

Государственный научно-технический центр по ядерной и радиационной безопасности, г. Киев, Украина

\section{Основные требования} к кабельным изделиям

\section{систем, важных для безопасности АЭС}

Рассмотрены особенности эксплуатационных условий кабельных линий в составе систем, важных для безопасности АЭС. Приведена классификация кабельных изделий, а также основные требования к кабельным изделиям, обеспечивающие ядерную и радиационную безопасность эксплуатации АЭС.

Ключе вые слов а: атомная электрическая станция, кабельные изделия, пожарная безопасность, надежность.

\section{О. О. Іокст, В. О. Іокст, Л. С. Івашова, К. М. Єфімова, В. В. Левакін}

Основні вимоги до кабельних виробів систем, важливих для безпеки AEC

Розглянуто особливості експлуатаційних умов кабельних ліній в складі систем, важливих для безпеки АЕC. Наведено класифікацію кабельних виробів, а також основні вимоги до кабельних виробів, що забезпечують ядерну та радіаційну безпеку експлуатації АEC.

Ключові слова: атомна електрична станція, кабельні вироби, пожежна безпека, надійність.

() Е. А. Иокст, В. А. Иокст, Л. С. Ивашова, К. М. Ефимова, В. В. Левакин,

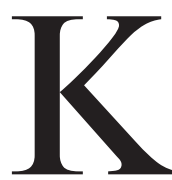

абельные изделия как составная часть каждой системы контроля и управления АЭС несут важнейшие функции передачи информации и организации надежного электропитания поСогласно «Комплексной (сводной) программе повышения уровня безопасности энергоблоков атомных электростанций», модернизации подлежит, в числе прочего, кабельное хозяйство, от надежности которого зависит надежность электроснабжения собственных нужд, систем управления, защиты и других систем АЭС [1].

В связи с проведением модернизации действующих систем на всех АЭС Украины возникает необходимость пересмотра и обновления действующей нормативной базы [2] и, в частности, необходимость создания специализированного нормативного документа, обобщающего требования к кабельным изделиям, применяемым на АЭС. Наличие такого документа позволит решить проблему комплексного подхода к организации поставок кабельных изделий специально для атомной промышленности.

Общие рекомендательные данные о конструкции и характеристиках кабелей для систем аварийного электроснабжения можно найти в руководстве [3] МАГАТЭ. В Российской Федерации в 2012 году приказом ОАО «Концерн Росэнергоатом» введен в действие СТО 1.1.1.01.001.0902-2012 «Кабельные изделия для атомных электростанций. Технические требования эксплуатирующей организации». Среди стандартов Международной электротехнической комиссии (МЭК) есть множество таких, которые содержат технические требования для различных типов кабелей, однако нет документа, объединяющего требования к кабельным изделиям для АЭС.

В данной статье предпринята попытка рассмотреть и обобщить данные национальных нормативных документов в части требований по ядерной и радиационной безопасности применительно к кабельным изделиям.

Эксплуатация кабельных изделий на АЭС имеет свои особенности, диктуемые: а) условиями эксплуатации, которые характеризуются повышенным уровнем таких деградационных факторов, как температура, ионизирующие излучения, влажность, химически активная среда, механические нагрузки; б) обеспечением работоспособности кабельных линий герметического ограждения (ГО) во время и после проектных/запроектных аварий.

Номенклатура кабельных изделий, удовлетворяющих условиям применения в кабельных сооружениях и технологических помещениях атомных станций, включает специальные типы терморадиационностойких кабелей и проводов, используемых в ГО АЭС, кабели для оборудования систем безопасности и систем, важных для безопасности атомных станций. В системах, не влияющих на безопасность, могут использоваться кабели и провода общепромышленного назначения, которые по своим техническим показателям удовлетворяют требованиям, установленным для применяемого на АЭС оборудования.

Используемые для АЭС кабельные изделия нового поколения имеют особую маркировку, которая отражает их соответствие отдельным показателям пожарной безопасности (или их совокупности) и включает такие буквенные индексы:

«нг» - соответствие требованиям по нераспространению горения при групповой прокладке, ГОСТ 12176-89 (МЭК 332-3-82);

«LS» (low smoke) - соответствие требованиям по дымообразованию при горении: кабели, не распространяющие 
горение при групповой прокладке с низким дымо- и газовыделением при горении, ДСТУ 4367-1:2004, ДСТУ 4367-2:2014;

«HF» (halogen free) - соответствие требованиям по коррозионной активности продуктов дымо-, газовыделения при горении: кабели, не распространяющие горения, не содержашие галогенов в составе изоляции и оболочки, ДСТУ ІЕС 60754-2:2006;

«FR» (fire resistance) - соответствие требованиям по огнестойкости: кабели, не распространяющие горение, огнестойкие, ДСТУ ІЕС 60331-11:2008, ДСТУ IЕС 60331-21:2008, ДСТУ ІЕС 60331-23:2008, ДСТУ ІЕС 60331-25:2008.

В зависимости от класса напряжения и назначения проложенного кабеля кабельные линии делятся на следующие группы:

высоковольтные (кабель напряжением 35 кВ; 110 кВ; 220 кВ; 330 кВ; 500 кB; 750 кВ);

силовые (до $20 \mathrm{kB}$ );

контрольные, включая специальные кабели автоматизированных систем контроля и управления;

кабели связи;

волоконно-оптические линии.

Высоковольтные кабели напряжением 35 кВ и выше предназначены для передачи электроэнергии большой мощности. Их конструкция требует наличия таких элементов, которые должны обеспечить надежность и долговечность использования, обладать высокими механическими и диэлектрическими свойствами. Изоляция в таких кабелях может быть бумажно-масляной либо из сшитого полиэтилена.

Силовые кабели предназначены для передачи и распределения электрической энергии токами промышленных частот. Выпускаются с медными и алюминиевыми токопроводящими жилами с изоляцией из бумажных лент, пропитанных маслом или специальными составами, а также с изоляцией из поливинилхлоридного пластиката, сшитого полиэтилена, резины. Имеют свинцовые, алюминиевые или пластмассовые оболочки. Диапазон переменного напряжения, в котором используются силовые кабели, - от 660 В до 20 кВ.

Контрольные кабели предназначены для питания приборов, аппаратов и других электротехнических устройств. Используются в цепях контроля и измерения электрических и физических параметров. Имеют токопроводящие жилы из меди, биметалла алюминий-медь, алюминия.

Кабели управления используются в цепях дистанционного управления, релейной защиты и автоматики. В качестве изоляции служат поливинилхлоридный пластикат, фторопласт, резина. Число токоведущих жил - от 2 до 108. Все или отдельные токопроводящие жилы могут быть экранированными. Оболочки кабелей - пластмассовые, поверх оболочек может накладываться панцирная броня из стальных проволок. Форма кабелей управления - круглая или плоская.

Кабели связи предназначены для передачи сигналов связи информации токами различных частот. Делятся на высокочастотные и низкочастотные. Высокочастотные это кабели дальней связи, низкочастотные - местной связи. Имеют медные жилы и бумажную или пластмассовую изоляцию (поливинилхлоридный пластикат, полистирол). Изоляция может быть комбинированной: воздушно-бумажной или воздушно-полиэтиленовой. Оболочки кабелей связи - свинцовые, алюминиевые, стальные, пластмассовые или металлопластмассовые.

Волоконно-оптическая линия (ВОЛ) представляет собой состояшую из пассивных и активных элементов волоконно-оптическую систему, которая предназначена для передачи информации в оптическом диапазоне. ВОЛ выполняются волоконно-оптическими кабелями или проводами, состоящими из одной или нескольких стеклянных или пластиковых нитей, которые используются для переноса света внутри себя. Оптические кабели делятся на две группы: одномодовые и многомодовые. Наружная оболочка кабеля изготавливается из различных материалов, например поливинилхлорида, полиэтилена, полипропилена, тефлона. Оптический кабель может иметь бронирование различного типа и специфические защитные слои.

По способу прокладки кабельные линии делятся на кабельные линии, проложенные:

с креплением скобами по стене;

с креплением на тросе;

в кабельных металлоконструкциях;

в трубах;

в траншеях в земле;

в воде.

Прокладка основных кабельных потоков по территории площадки АЭС предусматривается в кабельных тоннелях и эстакадах, а небольших потоков кабеля - в каналах.

Кабели систем безопасности прокладываются в кабельных помещениях, туннелях, кабельных каналах и кабельных шахтах.

В зависимости от характера окружающей среды в зоне прокладки кабеля, условия эксплуатации кабельных линий делятся на:

нормальные условия, когда параметры окружающей среды имеют номинальные нормируемые изменяющиеся или неизменные верхнее и нижнее значения внешних воздействующих факторов, в пределах которых обеспечивается заданное работоспособное состояние;

условия повышенной температуры, когда происходит повышение температуры конструктивных элементов при наличии термических внешних воздействующих факторов: высокой температуры окружающей среды, электрического поля, при облучении ионизирующим излучением;

условия повышенной влажности;

условия агрессивной среды, когда есть внешние воздействующие факторы среды, которые вызывают или могут вызвать ограничение или потерю работоспособного состоянии изделия в процессе эксплуатации, в том числе в зонах контролируемого доступа (условия воздействия дезактивирующих растворов);

условия влияния внешних механических воздействий.

При выборе кабельных изделий для систем, важных для безопасности АЭС, должны быть в первую очередь определены:

- класс безопасности в соответствии с [4];

- условия эксплуатации:

- внутри гермозоны АЭС;

- вне гермозоны АЭС;

- категория сейсмостойкости в соответствии с [5].

На основании этих данных формируются требования к изделиям.

В состав группы кабельных изделий для использования на АЭС могут быть включены кабельные изделия, удовлетворяющие комплексу следующих технических требований.

Кабели для применения в ГО АЭС должны быть работоспособны при параметрах среды в гермозоне в режимах, в которых они должны выполнять свои функции, включая 
аварии «малой» и «большой» течи, а также режим запроектной аварии.

Кабельные изделия, предназначенные для эксплуатации при стационарной прокладке вне гермозоны АЭС, должны быть стойкими к воздействию ионизирующего излучения, изменению температуры, изменению влажности окружающей среды и, в зависимости от группы помещений в зоне строгого или свободного режима должны выполнять возложенные на них функции в течение срока службы.

Крайне актуальной является проблема гарантированного обеспечения сейсмостойкости важного для безопасности АЭС оборудования. Для АЭС понятие «сейсмостойкость» подразумевает гарантию обеспечения ядерной и радиационной безопасности при землетрясениях. К сейсмостойкости систем безопасности АЭС должны применяться гораздо более строгие требования по обеспечению вибропрочности и виброустойчивости оборудования, недопущению выхода из строя и нарушений функционирования технологических систем, важных для безопасности.

Кабельные изделия, применяемые в системах безопасности АЭС, должны быть устойчивыми (выполнять предусмотренные функции в заданном объеме) при воздействии вибрации и механических ударов, источниками которых является работающее технологическое оборудование, в рабочих условиях эксплуатации без ограничения времени. Кабельные изделия категории сейсмостойкости I должны быть устойчивыми при воздействии вибрации и механических ударов, вызванных максимальным расчетным землетрясением (МР3) на площадке АЭС. Кабельные изделия категории сейсмостойкости II должны выполнять предусмотренные функции в заданном объеме после воздействия на них вибрации и механических ударов, вызванных проектным землетрясением (ПЗ) на площадке АЭС.

В части требований пожарной безопасности кабели делят на следующие классы:

по способности к сохранению целостности цепей в условиях комбинированного действия пламени температурой не менее $830{ }^{\circ} \mathrm{C}$ и механического удара;

по способности к сохранению целостности цепей в условиях воздействия пламени, температура которого не меHeе $750{ }^{\circ} \mathrm{C}$;

по способности к сохранению целостности цепей в условиях стандартного температурного режима;

по коррозионной активности продуктов сгорания их неметаллических элементов;

по дымообразующей способности во время пламенного горения;

по дымообразующей способности во время тления;

по токсичности продуктов сгорания их неметаллических элементов;

по стойкости к распространению пламени при условии прокладки в пучках;

по стойкости к распространению пламени при условии одиночной прокладки.

Основным горючим материалом электрических кабелей, определяющим потенциальную опасность пожара, является изоляция, в том числе изоляция кабелей, относящихся к категориям огнестойких и нераспространяющих горение.

Нераспространение горения характеризует способность кабеля к самозатуханию после прекращения воздействия источника пламени. Количественно этот показатель оценивают по длине поврежденного участка кабеля после прекращения его горения.
Дымообразование при горении кабеля характеризуется максимальной удельной оптической плотностью среды в камере при сгорании образца. Этот показатель отражает развитие во времени задымленности в помещении при пожаре и в значительной степени определяет условия тушения пожара.

Коррозионная активность продуктов газовыделения приводит к разрушению электрооборудования в помещениях и, таким образом, увеличивает ущерб от пожара. Количественно этот показатель характеризуется количеством выделения таких активных продуктов, как хлористый водород $\left(\mathrm{HC}_{1}\right)$, бромистый водород $(\mathrm{HBг),} \mathrm{диоксид}$ серы $\left(\mathrm{SO}_{2}\right)$ и т. п.

Токсичность продуктов газовыделения, как правило, является одной из причин несчастных случаев при пожаpax. К токсичным продуктам прежде всего относят цианистый водород $(\mathrm{HCN})$, аммиак $\left(\mathrm{NH}_{3}\right)$, диоксид серы $\left(\mathrm{SO}_{2}\right)$, сероводород $\left(\mathrm{H}_{2} \mathrm{~S}\right)$, оксид углерода (CO).

Огнестойкость кабеля характеризуется сохранением его работоспособности при воздействии открытого пламени в течение установленного времени (от 15 мин до 3 ч).

Показатели пожарной безопасности кабелей определяются, в основном, выбором материалов изоляции и защитных покрытий, а также конструктивным исполнением кабелей.

Для полимерных изоляционных материалов установлены такие показатели пожарной безопасности, как горючесть, кислородный индекс, коэффициент дымообразования, токсичность продуктов горения.

Горючесть характеризует способность материала к горению. При этом выделяются материалы негорючие - не способные к горению в воздухе; трудногорючие - способные возгораться в воздухе, не способные самостоятельно гореть после удаления источника зажигания; горючие - способные самовозгораться, а также самостоятельно гореть после удаления источника зажигания.

Класс пожарной безопасности всех типов кабельных изделий в соответствии с классификацией [6] должен быть приведен в нормативном документе на кабельные изделия конкретных марок.

В соответствии с [7] кабели для АЭС должны удовлетворять требованию нераспространения горения; кабели переменного и постоянного тока до 10 кВ включительно должны соответствовать условиям невозгорания (пожарной стойкости) при их нагреве токами короткого замыкания.

Надежная и бесперебойная работа кабеля в значительной мере зависит от качества электрической изоляции, которая обеспечивает необходимую независимость токопроводящих жил по отношению друг к другу и к заземлённой оболочке (земле). Изоляция должна иметь такую электрическую прочность, чтобы возможность электрического пробоя ее при напряжении, на которое рассчитан кабель, была исключена. Сопротивление изоляции кабельных изделий должно соответствовать требованиям [8].

Требования к электромагнитной совместимости обусловлены способностью кабельной системы, соединяющей активные устройства, как излучать, так и подвергаться воздействию электромагнитных излучений.

Одними из важнейших задач при рассмотрении воздействия электромагнитных полей на различные структуры электротехнических систем являются:

определение стойкости силовых кабельных линий высокого и низкого напряжения; 
определение помехозащищенности информационных каналов систем управления по отношению к действию внешних электромагнитных излучений различного происхождения;

оценка соответствующих токов и напряжений, наводимых этими излучениями в линиях.

При этом под внешними понимаются излучения, генерируемые в широком диапазоне частот внешними по отношению к кабельным линиям источниками различного происхождения. В качестве таких источников могут выступать различные элементы электротехнических систем, генерирующие электромагнитные поля, например расположенные вблизи линии электропередачи, коммутационные устройства и токоограничители, приемники и преобразователи электрической энергии низкого и высокого напряжения, электрические молниевые разряды, источники ионизирующего излучения и т. д.

Проблема экранирования кабельных линий приобретает особую значимость при решении вопросов эффективной защиты информационных потоков в системах управления, связи и телекоммуникации, используемых на АЭС. Поэтому и возникает необходимость оценки степени воздействия внешних электромагнитных полей, а также наводимых ими в экранах и жилах кабеля напряжений и токов на полезный сигнал в линии, а следовательно, на показатели качества электрической энергии - для силовых (питающих) кабельных линий и вторичных цепей, и достоверность передаваемой информации (управляющих сигналов) - для кабельных линий систем управления и систем связи.

Учет электромагнитной совместимости силовых, вторичных и информационных кабельных линий с другими элементами рассматриваемой электротехнической системы позволяет предупредить неблагоприятные воздействия внешних электромагнитных источников [9]. Примерами последствий таких воздействий могут быть ухудшение показателей качества электроэнергии, передаваемой по кабельной линии, а также нагрев оболочек и, следовательно, увеличение потерь в линии, пробои изоляции кабелей, ложные срабатывания устройств релейной защиты и автоматики.

Для обеспечения надежной работы систем безопасности АЭС применяемые кабели должны соответствовать требованиям электромагнитной совместимости как в рамках исключения взаимного влияния между собой, так и в условиях воздействия на них помех, вызванных работой или нарушениями в работе технологического оборудования АЭС и средств автоматизации, природными явлениями и действиями персонала.

Основными видами электромагнитных помех кабельных линий являются:

разряды статического электричества на внешние экраны кабелей;

наносекундные импульсные помехи, поступающие от внешних источников на информационные цепи и цепи питания;

радиочастотные помехи;

магнитные поля промышленной частоты;

импульсные магнитные поля;

кратковременные или микросекундные синусоидальные помехи в цепях защитного заземления.

В зависимости от назначения кабельных линий, класса безопасности по [4] и от жесткости электромагнитной обстановки при их эксплуатации, для кабельных изделий в ТУ или Т3 должны быть определены группы исполнения по помехоустойчивости в соответствии с [10].
Кабельные изделия должны соответствовать требованиям Технического регламента по электромагнитной совместимости оборудования.

Уровень излучаемых помех при работе кабеля в системе не должен превышать значений, установленных для оборудования класса А по [11] и соответствовать требованиям [10].

Кабельные линии, располагаемые во всех помещениях зоны строгого режима, а также в технологических, периодически обслуживаемых помещениях зоны свободного режима АЭС, подвергаются воздействию специальных сред. К внешним воздействующим факторам специальных сред относят воду и растворы, орошающие кабели при аварийных режимах, а также дезактивирующие растворы. Кабельные изделия для АЭС в соответствии с [12] должны быть устойчивы к воздействию орошающих растворов, а также допускать периодическую обработку дезактивирующими растворами; химический состав, продолжительность обработки и температура растворов должны быть указаны в нормативных документах на кабельное изделие.

Кабельные изделия должны удовлетворять требованиям по показателям надежности - безотказности, ремонтопригодности и долговечности, - установленным в действующих нормативных документах.

Работоспособное состояние кабельных изделий должно сохраняться в течение нормируемых в стандартах или ТУ сроков.

Изготовление кабельной продукции промышленным предприятием для поставки на АЭС должно осуществляться только после выполнения комплекса процедур, установленных требованиями [13] по освоению производства изделий технического назначения (постановка на промышленное производство). Постановка кабельных изделий на серийное производство считается завершенной при условии положительных результатов испытаний, выполненных приемочной комиссией.

Для оиенки соответствия кабелей, поставляемых на АЭС, требованиям ядерной и радиационной безопасности должны применяться следующие формы оценивания:

государственный контроль (надзор);

испытания;

приемка;

подтверждение соответствия.

Кабельные изделия не должны поставляться или применяться на АЭС, пока не будут завершены операции, указанные в планах качества, программах и методиках испытаний, с результатами, подтверждающими их соответствие установленным техническим требованиям.

Положительные результаты анализа и результаты оценки соответствия, подтвердившие соответствие параметров (характеристик) кабельных изделий требованиям, установленным в области использования атомной энергии, служат основанием для их применения на АЭС.

\section{Выводы}

Разработка отдельного специализированного стандарта, содержащего требования к кабельным изделиям, применяемым на АЭС, в том числе в системах безопасности, является актуальной темой в отрасли атомной промышленности. Подобный документ существенно прояснил бы подход к выбору кабельных изделий для систем, важных для безопасности АЭС, что позволило бы повысить надежность и безопасность эксплуатации АЭС. 


\section{Список использованной литературы}

1. Скрипчак Д. С. Надежность электрооборудования: мероприятия по повышению безопасности и продлению сроков эксплуатации энергоблоков АЭС Украины / Д. С. Скрипчак, К. М. Ефимова, В. В Инюшев // Ядерна та радіаційна безпека. 2012. - № 4. - C. 30-33

2. Розен Ю. В. Новые нормативные документы, регламентирующие требования к информационным и управляющим системам, важным для безопасности АЭС / Ю. В. Розен, М. А. Ястребенецкий // Ядерна та радіаційна безпека. - 2014. № 2. - C. $50-64$

3. IAEA NS-G-1.8:2004. Design of Emergency Power Systems for Nuclear Power Plants. - Vienna : International Atomic Energy Agency, 2004. - (Safety standards series, ISSN 1020-525X; no. NS-G-1.8) ISBN 92-0-103504-7.

4. НП-306.2.141-2008. Загальні положення безпеки атомних станцій. - К. : Державний комітет ядерного регулювання України, 2008. -35 с.

5. ПНАЭ Г-5-006-87. Нормы проектирования сейсмостойких атомных станций. - М. : Энергоатомиздат, 1989. - 28 с.

6. ДСТУ 4809-2007. ІІзольовані проводи та кабелі. Вимоги пожежної безпеки та методи випробування. - К. : Держспоживстандарт України, 2007. - 15 с.

7. НАПБ 03.005-2002 (ВБН B.1.1-034-03.307-2003). Противопожарные нормы проектирования атомных электростанций с во до-водяными энергетическими реакторами. - К. : М-во топлива и энергетики Украины, 2003. - 78 с.

8. СОУН EE 20.304:2009. Норми випробування силових кабельних ліній напругою до 500 кВ. - К. : М-во палива та енергетики України; Державне підприємство «Національна енергетична компанія "Укренерго"», 2009. - С. 43.

9. Евланов В. М. Влияние электрических и электромагнитных внешних воздействующих факторов на безопасность информационных и управляющих систем, важных для безопасности АЭС / В. М. Евланов, К. М. Ефимова // Ядерна та радіаційна безпека. - 2012. - № 2. - С. $30-35$

10. СОУ НАЕК 029:2012. Сумісність технічних засобів електромагнітна. Технічні засоби для атомних станцій. Вимоги та методи випробувань. - К. : Державне підприємство "Національна атомна енергетична компанія "Енергоатом"», 2012. $-96 \mathrm{c}$

11. ГОСТ 29216-91. Совместимость технических средств электромагнитная. Радиопомехи индустриальные от оборудования информационной техники. Нормы и методы испытаний. - М. : Госстандарт России, 1992. - 15 с.

12. ДСТУ ГОСТ 29075:2009. Системы ядерного приборостроения для атомных станций. Общие требования. - М. : Комитет стандартизации и методологии СССР, 1992. - 34 с.

13. КНД 95.0.02.02.004-97. Изделия для объектов ядерной энергии. Правила приемки. - К. : Госкоматом Украины, 1997. - 42 с.

\section{References}

1. Skripchak, D. S., Yefimova, K. M., Inyushev, V. V. (2012), "Tendency towards Increasing Reliability of Electrical Equipment through Safety Improvement and Long-Term Operation Measures at Ukrainian NPPs" [Nadiozhnost elektrooborudovaniia: Meropriiatiia po povysheniiu bezopasnosti i prodleniiu srokov ekspluatatsii energoblokov AES Ukrainy], Yaderna ta radiatsiina bezpeka (Nuclear and Radiation Safety), No. 4, pp. 30-33. (Rus)
2. Rozen, Yu. V., Yastrebenetsky, M. A. (2014), "New Regulatory Documents with Requirements for Instrumentation and Control Systems Important to NPP Safety" [Novyie normativnyie dokumenty, reglamentiruiushiie trebovaniia $\mathrm{k}$ informatsionnym i upravliaiuschim sistemam vazhnym dlia bezopasnosti AES], Yaderna ta radiatsiina bezpeka (Nuclear and Radiation Safety), No. 2, pp. 50-64. (Rus)

3. IAEA NS-G-1.8:2004. Design of Emergency Power Systems for Nuclear Power Plants, Safety Standards Series, ISSN 1020-525X; No. NS-G-1.8, Vienna, IAEA, 2004, ISBN 92-0-103504-7.

4. NP 306.2.141-2008. General Safety Provisions for Nuclear Power Plants [Zahalni polozhennia bezpeky atomnykh stantsii], Kyiv, State Nuclear Regulatory Inspectorate of Ukraine, 35 p. (Ukr)

5. PNAE G-5-006-87. Standards for Seismic Designs of Nuclear Power Plants [Normy proektirovaniia seismostoikikh atomnykh stantsii], Moscow, Energoatomizdat, 1989, 28 p. (Rus)

6. DSTU 4809-2007. Insulated Wires and Cables. Requirements for Fire Safety and Test Methods [Izoliovani provody ta kabeli. Vymohy pozhezhnoi bezpeky ta metody vyprobuvannia], Kyiv, Derzhspozhyvstandart Ukrainy, 2007, 15 p. (Ukr)

7. NAPB 03.005-2002 (VBN V.1.1-034-03.307-2003). Fire Protection Design Standards for WWER Nuclear Power Plants [Protivopozharnyie normy proektirovaniia atomnykh elektrostantsiis vodovodianymi energeticheskimi reaktorami], Kyiv, Ministry for Fuel and Energy of Ukraine, 2003, 78 p. (Rus)

8. SOU-N EE 20.304:2009. Regulation for Testing of Power Cable Lines with Voltage to $500 \mathrm{kV}$ [Normy vyprobuvannia sylovykh kabelnykh linii napruhoiu do $500 \mathrm{kV}$ ], Kyiv, Ministry for Fuel and Energy of Ukraine, National Energy Company Ukrenergo, 2009, p. 43. (Ukr)

9. Yevlanov, V. M., Yefimova, K. M. (2012), "Influence of Electric and Electromagnetic External Factors on the Safety of I\&C Systems Important to NPP Safety" [Vliianie elektricheskikh i elektromagnitnykh vneshnikh vozdeistvuiuschikh faktorov na bezopasnost informatsionnykh i upravliaiuschikh system, vazhnykh dlia bezopasnosti AES], Yaderna ta radiatsiina bezpeka (Nuclear and Radiation Safety), No. 2, pp. 30-35. (Rus)

10. SOU NAEK 029:2012. Electromagnetic Compatibility of Technical Means. Technical Means for Nuclear Power Plants. Requirements and Testing Methods [Sumisnist tekhnichnykh zasobiv elektromahnitna. Tekhnichni zasoby dlia atomnykh stantsii. Vymohy ta metody vyprobuvan], Kyiv, National Nuclear Energy Generating Company Energoatom, 2012, 96 p. (Ukr)

11. GOST 29216-91. Electromagnetic Compatibility of Technical Means. Industrial Radio Interference from Information Technology Equipment. Standards and Testing Methods [Sovmestimost tekhnicheskikh sredstv elektromagnitnaia. Radiopomekhi industrialnyie ot oborudovaniia informatsionnoi tekhniki. Normy I metody ispytanii], Moscow, Gosstandardt, 1992, 15 p. (Rus)

12. DSTU GOST 29075:2009. Systems of Nuclear Instrument Engineering for Nuclear Power Plants. General Requirements [Sistemy yadernogo priborostroieniia dlia atomnykh stantsii. Obschiie trebovaniial, Moscow, USSR Committee for Standardization and Methodology, 1992, 34 p. (Rus)

13. KND 95.0.02.02.004-97. Equipment for Nuclear Facilities. Acceptance Rules [Izdeliia dlia obiektov yadernoi energii. Pravila priiomki], Kyiv, Goskomatom of Ukraine, 1997, 42 p. (Rus) 